\title{
Passive Filter Design for Improving Quality of Solar Power
}

\author{
Nurhalim Dani Ali \\ Department of Electrical Engineering \\ Faculty of Engineering \\ Universitas Riau, Indonesia \\ Rahyul Amri \\ Department of Electrical Engineering \\ Faculty of Engineering \\ Universitas Riau, Indonesia
}

\author{
Noveri Lysbetti M \\ Department of Electrical Engineering \\ Faculty of Engineering \\ Universitas Riau, Indonesia
}

*corresponding

author:

Nurhalim

Dani

Ali,
Firdaus

Department of Electrical Engineering

Faculty of Engineering

Universitas Riau, Indonesia

Edy Ervianto

Department of Electrical Engineering

Faculty of Engineering

Universitas Riau, Indonesia

nurhalim@lecturer.unri.ac.id

\begin{abstract}
With the progress of industry, power electronic equipment is widely used in power system, it has produced serious harmonic distortion. It goes without saying that harmonic analysis is a very important subject in power system. The influence of harmonics dominant because it is permanent. This harmonic influence spread to energy systems, energy devices, and influential to the energy source. For that, it is necessary a tool that is able to overcome these problems so that the electric energy services are not compromised and the reliability was not reduced. This study how to harmonic analysis, total harmonic distortion, and identifying the inverter at a solar power plant $320 \mathrm{WP}$ in accordance with the IEEE 519-2014.
\end{abstract}

Keywords: Harmonic, THD, Inverter, Solar Power Plant 320WP, IEEE.

\section{INTRODUCTION}

Definition of a power quality problem is used in this book Any power problem manifested in voltage, current, or frequency deviations that results in failure or misoperation of customer equipment. The main purpose of the Power System is to transmit electrical power with constant voltage and frequency. However, there is a little possibility to fulfill this ideal conditional. It can not do well caused many varieties of disorders, including the generated harmonics by Non-Linear Loads will affect overall performance system. Harmonics on Electrical System is one of causes that influences quality of power.

Harmonics' influence is so dominant because it is permanent. This influence of harmonics spreads to energy systems and energy devices. It is also influential to energy source.
By these conditions, a tool can overcome these problems is needed, so electrical energy services are not disturbed and reliability is not decreased. Distortion is caused by harmonic current will disturb Sinusoidal Waves, so they become distortion and impure. These circumstances make the performance of equipment becomes disturbed, so it cannot work properly.

The main source of harmonics in Power System is NonLinear Loads. This study will identify harmonics are caused by inverter and load on Solar Power Plant.

\section{THEORETICAL BASIS}

\section{A. Solar Power Plant 320 WP}

Solar Power Plant is electrical source that very potential and environmental friendly. It is also one of energy alternative to replace Power Plant using steam (oil and coal).

Energy System of Solar Power Plant can reduce the world's dependence on fossil fuel. Free energy and continuously based on our earth, is provided to fulfill needs of energy and can reliably to reduce power release.

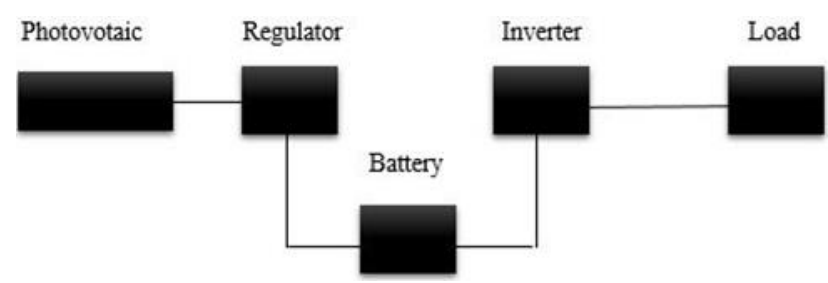

Figure 1: Solar power plant diagram 


\section{B. Harmonic}

Harmonic is one sinusoidal component from one wave period has integer multiplied frequency of its fundamental frequency. The distorted wave consists of many harmonics. First harmonic is known as basic frequency or fundamental frequency.

Harmonics with odd integer multiplied frequency from its fundamental frequency is called Odd Harmonic. On the other side, harmonics with even integer multiplied frequency from its fundamental frequency is called Even Harmonic.

Non-Linear Load is one type of harmonic equipment can change current wave or voltage wave to be a certain form which is not sinusoidal anymore.

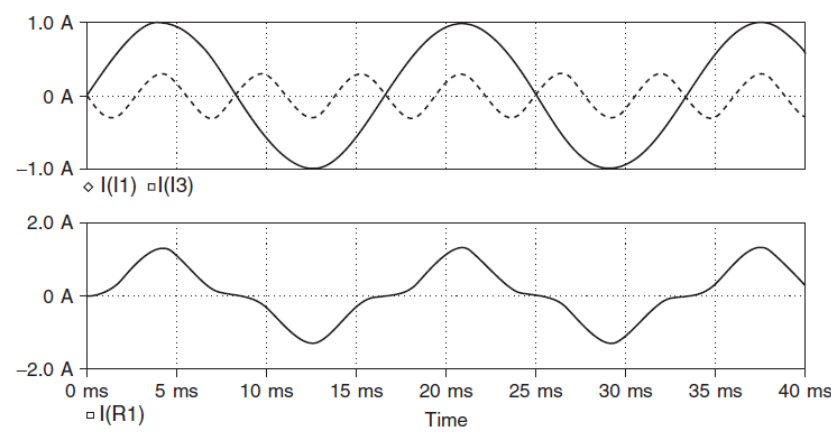

Figure 2: A Plot of the Fundamental and Third Harmonic Wave.

\section{Total Harmonic Distorsion}

There are voltage and harmonic current boundaries that can be tolerated in a Power System. They are called Total Harmonic Distortion (THD) Limits. THD limits are measured in meters on Power System.

Harmonic's content, both current and voltage, can be expressed as root mean square (rms) or Total Harmonic Distortion. Total harmonic is expressed as:

$\begin{aligned} T H D_{i} & =\frac{\sqrt{\sum_{2}^{\infty} I_{n}^{2}}}{I_{1}} \times 100 \% \\ T H D_{V} & =\frac{\sqrt{\sum_{2}^{\infty} V_{n}^{2}}}{V_{1}} \times 100 \%\end{aligned}$

Whereas:

$I_{n} / V_{n} \quad=$ Current $/$ Voltage harmonics on $n$-order

$I_{1} / V_{1}=$ Current/fundamental Voltage (Vrms)

$n \quad=2-50$ (value of calculated $n$ ranging from 2 to 50 $\left(50^{\text {th }}\right.$ harmonics $)$. Whereas $\mathrm{n}>50$, its harmonics are very small.

The inductive and capacitive parameter can be computed from equation (3) to (6) below.

$\mathrm{V}=\mathrm{I} \times \mathrm{Z}$

Value of $\mathrm{Z}$ can be obtained by using a formula in Equation 4.

Z=X_C-X_L

Whereas:

$\mathrm{X} \mathrm{C}=1 / 2 \pi \mathrm{fC}$
And:

$\mathrm{XL}=2 \pi \mathrm{fL}$

\section{Harmonic Standard}

Magnitude of harmonic's effect on Power System is determined by magnitude of resulted THD. Standard limits IEEE 519-2014 of Harmonic Voltage Distortion is shown in Table 1.

Table 1. Standard limits IEEE 519-2014 of Harmonic Voltage Distortion

\begin{tabular}{|l|l|l|}
\hline $\begin{array}{c}\text { Bus voltage V at } \\
\text { PCC }\end{array}$ & \multicolumn{1}{c|}{$\begin{array}{c}\text { Individual } \\
\text { Harmonic }(\%)\end{array}$} & \multicolumn{1}{c|}{$\begin{array}{c}\text { Total Harmonic Distortion } \\
\text { THD (\%) }\end{array}$} \\
\hline $\mathrm{V} \leq 1.0 \mathrm{kV}$ & 5.0 & 8 \\
\hline $1 \mathrm{kV}<\mathrm{V} \leq 69 \mathrm{kV}$ & 3.0 & 5 \\
\hline $\begin{array}{l}69 \mathrm{kV}<\mathrm{V} \leq 161 \\
\mathrm{kV}\end{array}$ & 1.5 & 2.5 \\
\hline $161 \mathrm{kV}<\mathrm{V}$ & 1.0 & $1.5^{*}$ \\
\hline
\end{tabular}

Standard limits of Harmonic Current Distortion can be seen in Table 2.

Table 2. Standards limits IEEE 519-2014 of Harmonic Current Distortion

\begin{tabular}{|l|l|l|l|l|l|l|}
\hline \multicolumn{7}{|c|}{ Maximum harmonic current distortion in percent of IL } \\
\hline \multicolumn{7}{|c|}{ Individual harmonic order (odd harmonics) } \\
\hline ISC/IL & $\begin{array}{l}\mathrm{h} \\
11\end{array}$ & $\begin{array}{l}11 \leq \mathrm{h}< \\
17\end{array}$ & $\begin{array}{l}17 \leq \mathrm{h}< \\
23\end{array}$ & $\begin{array}{l}23 \leq \mathrm{h}< \\
35\end{array}$ & $\begin{array}{l}35 \leq \\
\mathrm{h}\end{array}$ & $\begin{array}{l}\mathrm{TD} \\
\mathrm{D}\end{array}$ \\
\hline$<20$ & 4.0 & 2.0 & 1.5 & 0.6 & 0.3 & 5.0 \\
\hline $20-50$ & 7.0 & 3.5 & 2.5 & 1.0 & 0.5 & 8.0 \\
\hline $50-100$ & 10 & 4.5 & 4 & 1.5 & 0.7 & 12 \\
\hline $\begin{array}{l}100- \\
1000\end{array}$ & 12 & 5.5 & 5 & 2 & 1 & 15 \\
\hline$>1000$ & 15 & 7 & 6 & 2.5 & 1.4 & 20 \\
\hline
\end{tabular}

Table 2 is Standard limits IEEE 519-2014, recommended maximum values for current distortion. Current harmonic standards are determined by ratio of ISC/IL. Whereas, ISC is short-circuit current on Point of Common Coupling (PCC), IL is nominal fundamental load current.

\section{METHODS OF IMPLEMENTATION}

Implementation Methods to identify harmonic is to identify existing parameters in system (such as inverter and load) and Harmonic order.

\section{A. Inverter and Load Mounted}

DC-AC inverter is used to convert DC voltage input into AC voltage. Type of used inverter is USAT Power Inverter 1200 W. Specifications Power Inverter $1200 \mathrm{~W}$ is shown in Table 3. Flowchart of Research can be seen in Figure 3. 


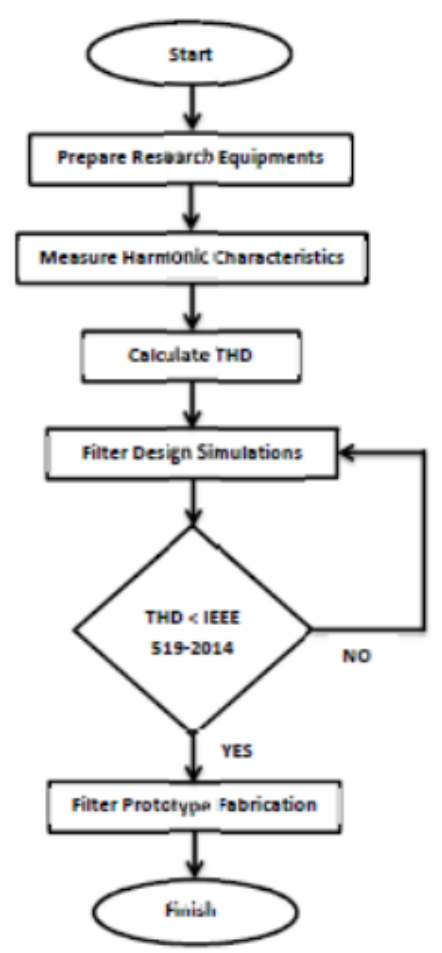

Figure 3: Flowchart of Research

Table 3. Specifications Power Inverter $1200 \mathrm{~W}$.

\begin{tabular}{|l|l|}
\hline \multicolumn{1}{|c|}{ Parameter } & \multicolumn{1}{|c|}{ Nominal Rating } \\
\hline DC Voltage Input $\left(\mathrm{V}_{\mathrm{IN}}, \mathrm{DC}\right)$ & $12 \mathrm{~V}$ \\
\hline AC Voltage Output $\left(\mathrm{V}_{\mathrm{OUT}}, \mathrm{DC}\right)$ & $200-300 \mathrm{~V}$ \\
\hline Output Power ( $\left.\mathrm{P}_{\mathrm{OUT}}\right)$ & $1200 \mathrm{~W}$ \\
\hline Maximum Efficiency $\left(\eta_{\mathrm{MAX}}\right)$ & $75 \%$ \\
\hline Fuse & $20 \mathrm{~A}$ \\
\hline Ignition Angle & $60^{\circ}$ \\
\hline
\end{tabular}

Installed load on system is load with alternating current. Load consists of static load and dynamic load with installed total capacity of $0.31 \mathrm{kVA}$, based on installed load.

\section{B. Simulation Model}

Based on contained data, simulation of Solar Power Plant 320WP with certain software. One line diagram Solar Power Plant 320 WP, can be seen in Figure 4.

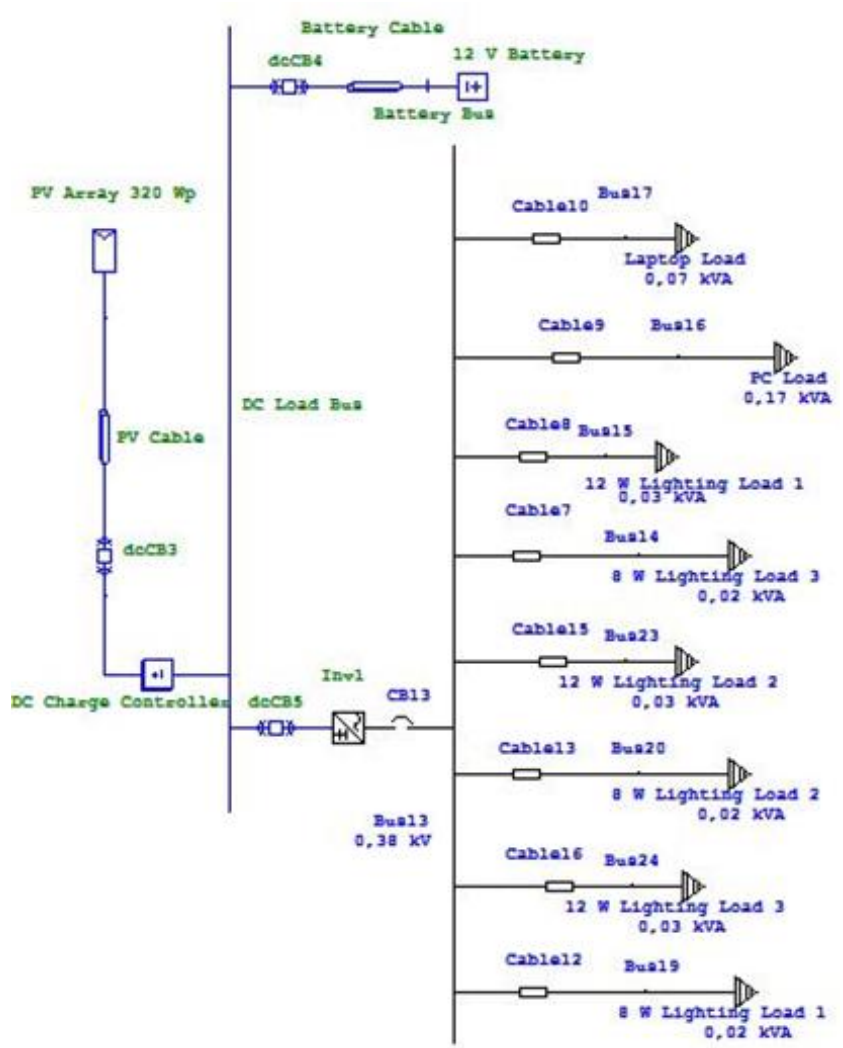

Figure 4: One line diagram Solar Power Plant 320 WP.

\section{RESUlts AND DisCUSSION}

\section{A. No-Load Condition}

From simulations on ETAP Software, can be seen results of harmonic waveform and harmonic spectrum from inverter output on No-Load Condition. Generated Harmonic Waveform from inverter output on No-Load Condition is shown in Figure 5.

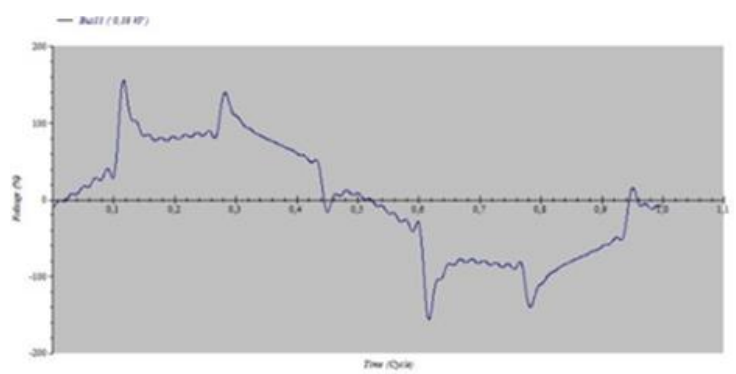

Figure 5: Harmonic wave form on No-Load Condition.

Generated Harmonic Spectrum-order from inverter output on No-Load Condition, can be seen in Figure 6.

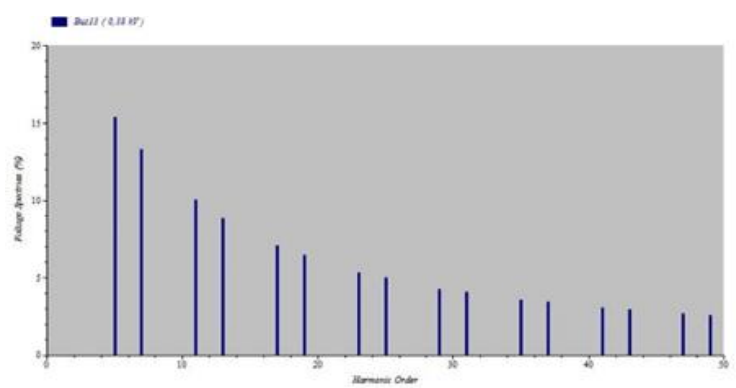


Figure 6: Generated Harmonic Spectrum-order from inverter output on No-Load Condition

From Figure 5 and Figure 6, can be seen that orders produce the biggest harmonics are harmonics 5, 7, 11 and 13. So, a passive filter type L-C on Bus 13 is designed. Percentage of Generated Harmonic magnitudes on No-Load Condition of each order is shown in Table 4.

Table 4. Percentage of Generated Harmonic magnitudes on No-Load Condition each order.

\begin{tabular}{|c|c|c|}
\hline Order & Frequency (Hz) & Magnitude (\%) \\
\hline 5 & 250 & 14,64 \\
\hline 7 & 350 & 17,84 \\
\hline 11 & 550 & 14,74 \\
\hline 13 & 650 & 10,87 \\
\hline 17 & 850 & 8,68 \\
\hline 19 & 950 & 4,21 \\
\hline 23 & 1150 & 2,42 \\
\hline 25 & 1250 & 2,22 \\
\hline 29 & 1450 & 3,34 \\
\hline 31 & 1550 & 4,87 \\
\hline 35 & 1750 & 5,32 \\
\hline 37 & 1850 & 5,10 \\
\hline 41 & 2050 & 4,68 \\
\hline 43 & 2150 & 3,25 \\
\hline 47 & 2350 & 2,37 \\
\hline 49 & 2450 & 28,87 \\
\hline Total & & \\
\hline
\end{tabular}

\section{B. Load Condition}

From simulations can be seen results of harmonic waveform and harmonic spectrum from inverter output on load condition. Generated Harmonic Waveform from inverter output on Load Condition, can be seen in Figure 7.

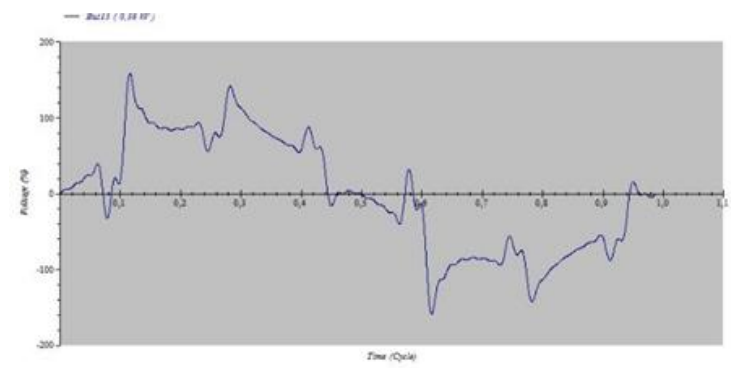

Figure 7: Generated Harmonic Waveform from inverter output on Load Condition

Generated Harmonic Spectrum-order from inverter output on Load Condition is shown in Figure 8.

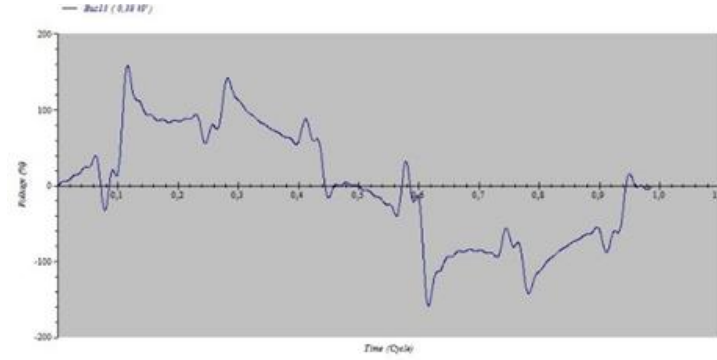

Figure 8: Generated Harmonic Specrum-order from inverter output on Load Condition

From Figure 7 and Figure 8, can be seen that waveform and spectrum from order 5, 7, 11, 13 are also same on Load Condition but the biggest percentage are $17.84 \%$, and $16,10 \% 14,74 \%$ from orders 7 , and 11 . Percentage of Generated Harmonics on Load Condition of each order can be seen in Table 5 .

Table 5. Percentage of Generated Harmonics on Load Condition of each order

\begin{tabular}{|c|c|c|}
\hline Order & Frequency $(\mathrm{Hz})$ & Magnitude (\%) \\
\hline 5 & 250 & 14,64 \\
\hline 7 & 350 & 17,84 \\
\hline 11 & 550 & 16,10 \\
\hline 13 & 650 & 14,74 \\
\hline 17 & 850 & 10,87 \\
\hline 19 & 950 & 8,68 \\
\hline 23 & 1150 & 4,21 \\
\hline 25 & 1250 & 2,42 \\
\hline 29 & 1450 & 2,22 \\
\hline 31 & 1550 & 3,34 \\
\hline 35 & 1750 & 4,87 \\
\hline 37 & 1850 & 5,32 \\
\hline 41 & 2050 & 5,10 \\
\hline 43 & 2150 & 4,68 \\
\hline 47 & 2350 & 3,25 \\
\hline 49 & 2450 & 2,37 \\
\hline \multicolumn{2}{|l|}{ Total } & 36,86 \\
\hline
\end{tabular}

\section{Design of Filter Parameters}

Values of system as seen from measuring instrument PQA are:

$$
\begin{aligned}
& \mathrm{V}=218,6 \text { Volt }, \quad \mathrm{A}=0,494 \text { Ampere } \\
& \mathrm{PF}=0,173, \mathrm{PA}=0,98 \mathrm{THD}=28,7 \%
\end{aligned}
$$

Value of XC and XL already exists and consumed current of 5th order harmonic is 8.8 Ampere. For other calculations, using formula for each order can be repeated.

From Equation 3 to Equation 5 and by calculating MVAR, filter value can be determined. Results of filter value calculation are shown in Table 6. 
Table 6. Results of filter value calculation

\begin{tabular}{|l|l|l|l|l|}
\hline & Order-5 & Order-7 & Order-11 & Order-13 \\
\hline Mvar & $1,848 \times 10^{-3}$ & $1,848 \times 10^{-3}$ & $1,848 \times 10^{-3}$ & $1,848 \times 10^{-3}$ \\
\hline $\mathrm{X}_{\mathrm{C}}$ & $26,19 \mathrm{Ohm}$ & $26,19 \mathrm{Ohm}$ & $26,19 \mathrm{Ohm}$ & $26,19 \mathrm{Ohm}$ \\
\hline $\mathrm{C}$ & $121,5 \mu \mathrm{F}$ & $121,5 \mu \mathrm{F}$ & $121,5 \mu \mathrm{F}$ & $121,5 \mu \mathrm{F}$ \\
\hline $\mathrm{X}_{\mathrm{L}}$ & $1,136 \mathrm{Ohm}$ & $0,566 \mathrm{Ohm}$ & $0,224 \mathrm{Ohm}$ & $0,16 \mathrm{Ohm}$ \\
\hline $\mathrm{L}$ & $3,61 \mathrm{mH}$ & $1,8 \mathrm{mH}$ & $0,713 \mathrm{mH}$ & $0,509 \mathrm{mH}$ \\
\hline
\end{tabular}

\section{Testing Results Filter Passive L-C in Real Condition.}

From simulation results and initial test in real conditions can be determined value of filter. This test is done to look at generated harmonics by inverter on Load Condition. Result of wave inverter can be seen in Figure 8.

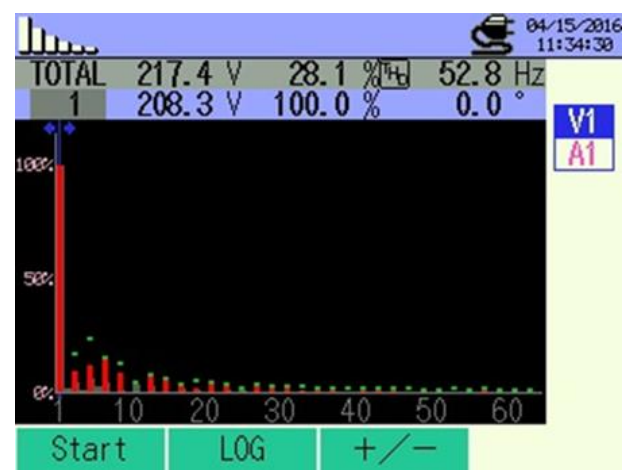

Figure 8: The resulting wave inverter

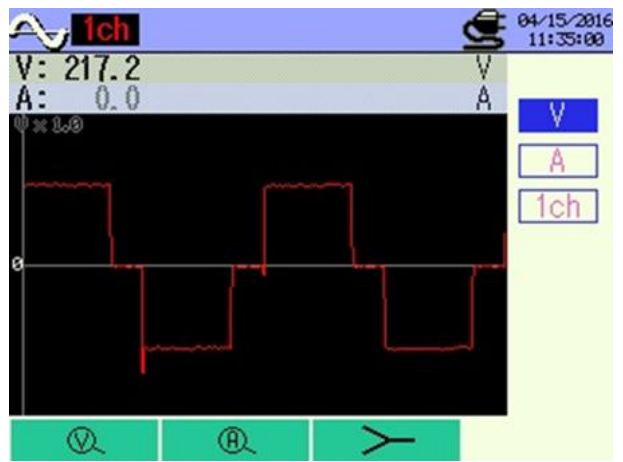

Firgure 9: The resulting spectrum inverter

From Figure 9 can be seen that different value between simulation with the real. THD simulation value is $28,78 \%$ while $28,01 \%$ real condition value. Real test condition can be seen spectrum value from PQA display. Percentage of generated harmonic on each order from inverter on load condition is shown in Table 8.

Table 8. Percentage of Generated Harmonic on each order from Inverter on Load Condition

\begin{tabular}{|l|l|l|}
\hline Order & \multicolumn{1}{|c|}{ Frekuensi (Hz) } & \multicolumn{1}{c|}{ Magnitude (\%) } \\
\hline 1 & 50 & 100 \\
\hline 3 & 150 & 9,53 \\
\hline 5 & 250 & 11,32 \\
\hline 7 & 350 & 16,01 \\
\hline 9 & 450 & 8,63 \\
\hline 11 & 550 & 5,01 \\
\hline 13 & 650 & 7,45 \\
\hline
\end{tabular}

\section{E. Test Harmonic in Real Condition With L-C Filter}

In this test, a filter has already be paralleled with system as load, because filter current is too large, so test result can not get optimal results. To get harmonic and load impedance, can be done by adding two transformers. Each transformer capacity is $20 \mathrm{~A}$. It can be seen from PQA display that generated current value is very large. Current value in-order output filter 5, can be seen in Fugure 9.

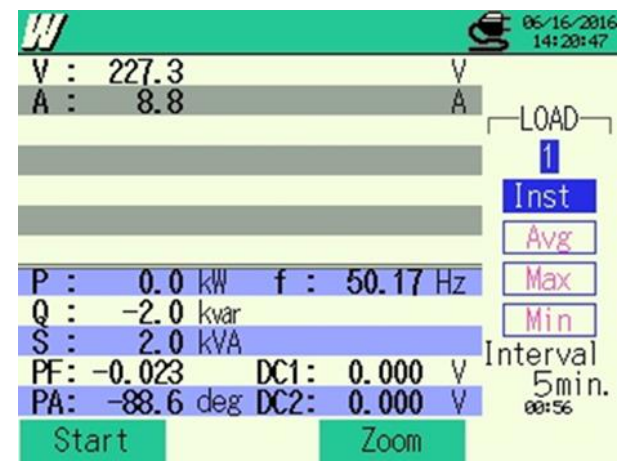

Figure 10: Large current in-order output filters 5.

From the test with a load using a transformer obtained results at 11 and 12 picture, the picture is not already installed filter systems 11 and 12 images are mounted filter system adapt comparison voltage drop after the installed filter. Testing result system before installing the filter is shown in Figure 11.

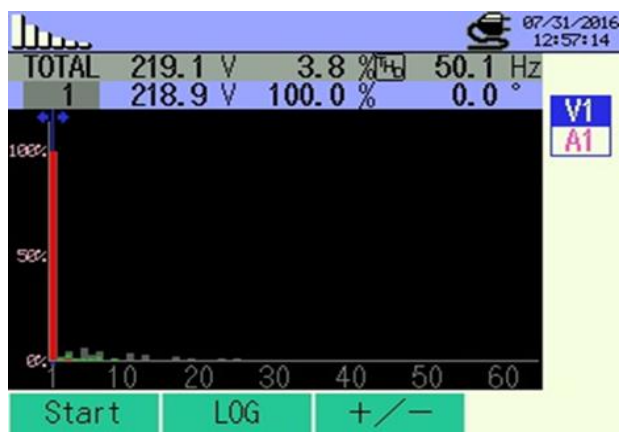

Figure 11: Tests on the system before the filter is installed

From Figure 11, value of each harmonic order is shown in Table 9.

Table 9. Percentage of Generated harmonic of each order of transformer on Load Condition without Filter

\begin{tabular}{|l|l|l|}
\hline Order & Frekuensi $(\mathbf{H z})$ & Magnitude $(\%)$ \\
\hline 1 & 50 & 100 \\
\hline 3 & 150 & 3,43 \\
\hline 5 & 250 & 7,21 \\
\hline 7 & 350 & 6,03 \\
\hline 9 & 450 & 1,67 \\
\hline 11 & 550 & 4,93 \\
\hline 13 & 650 & 3,02 \\
\hline
\end{tabular}


Testing system after installed filter can be seen in Figure 12 that shows harmonic filter can reduce harmonic level in the system.

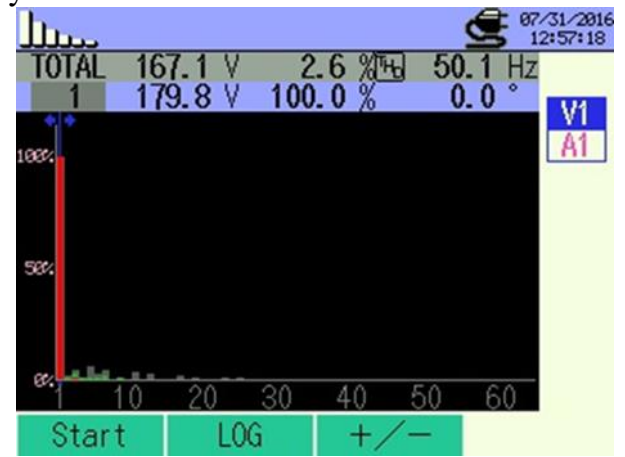

Figure 12: Tests on the system after it is installed a filter

Table 10. The harmonic value on load system with filter

\begin{tabular}{|l|l|l|}
\hline Order & Frekuensi $\mathbf{( H z )}$ & Magnitude $\mathbf{( \% )}$ \\
\hline 1 & 50 & 100 \\
\hline 3 & 150 & 2,59 \\
\hline 5 & 250 & 6,79 \\
\hline 7 & 350 & 5,51 \\
\hline 9 & 450 & 1,02 \\
\hline 11 & 550 & 4,12 \\
\hline 13 & 650 & 3,01 \\
\hline
\end{tabular}

\section{CONCLUSIONS}

Based on the results of simulation and analysis, it can be concluded that:

1. THD for No-Load Condition is $28.78 \%$ and $36.86 \%$ for Load Condition. THD is increased significantly because one of attached loads is Computer.

2. Wavefrom and spectrum from order 5, 7, 11, 13 are also same as load condition but the biggest percentage are $17.84 \%$, and $16,10 \% 14,74 \%$ from orders 7 , and 11.on Load Condition and No-Load Condition.
3. Even if the filter can reduce harmonic current consumed but very large filter, which causes a drop in the inverter.

\section{ACKNOWLEDGMENT}

We thank to Ministry of Research, Technology and Higher Education from Republic of Indonesia for funding this research in 2016 Hibah Bersaing Scheme. Many thanks go to our student Anggoro Arso Pambudi for providing a friendly.

\section{REFERENCES}

[1] Dugan, Roger C., McGranaghan, Mark F., Beaty, H. Wayne, "Electrical Power System Quality, McGraw-Hill," 2014

[2] Nurhalim ,"Identifying Characteristic of Power Quality Problems on Solar Electric Power Generator," The 1st International Conference on Science and Engineering for Instrumentation, Environment and Renewable Energy (ICoSE2015), Sep. 2015.

[3] Nurhalim, Azriyenni, Firdaus and S. Bahri, "Solar Electric Power Generator (SEPG) as a solution for peak load in household sector as energy conservation system: A case study in Pekanbaru City of Indonesia," 2011 International Conference \& Utility Exhibition on Power and Energy Systems: Issues and Prospects for Asia (ICUE), Pattaya City, pp. 1-4, 2011.

[4] Alexander Kusko., Marc T. Thomson. "Quality in Electrical Systems, The McGraw-Hill Company," 2007

[5] IEEE, Manjesh, Ananda A S, "Analysis and Study of Total Harmonic Distortion in Five Phase PWM Inverter using LC filter with neutral point DC link capacitor voltage balancing scheme," 9781-4799-5202-1/14, 2014.

[6] A. Manivannan, G. Murali, "Analysis of Power Quality Problems in Solar Power Distribution System," International Journal of Engineering Research and Applications (IJERA), Vol. 3, Issue 2, 2013.

[7] IEEE. "IEEE Recommended Practices and Requirements Harmonik Control in Electric Power System (IEEE Std 519-2014)," IEEE Inc, New York, NY 10016-2997, USA., 2014.

[8] Arillaga, Jos., Neville R. Watson, "Power System Harmonic. Jhon Wiley \& Sons, Ltd, New Zealand," 2003. 